\title{
Richness is not all: how changes in avian functional diversity reflect major landscape modification caused by pine plantations
}

David Lindenmayer $^{1,2}$, Wade Blanchard ${ }^{1}$, Philip Tennant ${ }^{1,2}$, Philip Barton ${ }^{1}$, Karen Ikin ${ }^{1,2}$, Alessio Mortelliti ${ }^{1,2}$, Sachiko Okada $^{1,2}$, Mason Crane ${ }^{1,2}$, Damian Michael $^{1}$

${ }^{1}$ Fenner School of Environment and Society, The Australian National University, Canberra, ACT, 2601

${ }^{2}$ Australian Research Council Centre of Excellence for Environmental Decisions; National Environmental Research Program; and Long-term Ecological Research Network, Fenner School of Environment and Society, The Australian National University, Canberra, ACT, 2601

Running head: Biotic responses to landscape transformation Article type: Biodiversity Research and Reviews 


\section{(A) ABSTRACT}

Aim: To quantify changes over a 15 -year period in bird functional diversity within woodland patches where woodland patches remained unchanged but the surrounding landscape context has been altered by exotic plantation establishment.

Location: South-eastern Australia.

Methods: Using statistical modelling, and Principal Co-ordinate Analysis, we explored how a suite of functional diversity measures, bird species richness, and the composition of the bird assemblage changed over time and in response to key covariates including: time since plantation establishment, woodland patch size, number of woodland patch boundaries surrounded by plantation, and woodland vegetation type.

Results: There was no significant change in species richness over time (with woodland patch size being the only significant effect on this measure). In contrast, we identified marked changes in the composition of bird assemblages, as well as significant temporal changes in functional diversity. The most substantial declines in functional diversity occurred in woodland patches completely surrounded by long-established stands of Radiata Pine. Plantation age also affected the functional diversity of bird assemblages through attracting new (typically closed forest-associated) species to the region. We also found reduced overlap in the amount of functional trait space defined by sets of species surveyed in successive years. This was linked to a shift away from solitary or pair-forming species found in open woodland environments and which consume seeds and various other food resources, towards insectivorous, nectarivorous and closed forest-associated taxa that occur in flocks or groups. 
Main Conclusions: Examination of temporal changes in functional diversity added new insights into the biotic changes associated with landscape transformation, and the functional role of species being replaced.

Keywords: Functional traits, functional richness, bird assemblage, plantation 


\section{(A) INTRODUCTION}

Major human-driven transformations of landscapes are increasingly common (Watson et al., 2014). These transformations include clearing of native vegetation and its replacement by agricultural croplands and grazing areas (Tscharntke et al., 2012), conversion of agricultural areas to timber plantations (Felton et al., 2010), the regeneration of forest on abandoned former agricultural land (Smith et al., 2010), and the conversion of natural and cleared areas to urban settlements (Forman 2014).

Landscape transformations are typically accompanied by significant changes in biodiversity (Kremen et al., 2007; Watson et al., 2014). Much of the focus in documenting the impacts of landscape transformation on biodiversity has been on changes in metrics like species richness (Dornelas et al., 2014) and the response of individual species (Lindenmayer et al., 2008a). Increasingly, focus is shifting to the diversity of ecological and biological traits (e.g. foraging guild, body size, movement patterns) occurring among sets of species in a given ecosystem, often referred to as 'functional diversity' (Tilman 2001; Petchey \& Gaston 2002; Schleuter et al., 2010; Cadotte et al., 2011; Weiher 2011). Using this approach to examining biodiversity, it is possible to gain mechanistic insights into the processes affecting community assembly (Lavorel \& Garnier 2002), such as species sorting along environmental gradients or between contrasting habitats (McGill et al., 2006; Weiher 2011; Hanspach et al., 2012). Despite this, there has been only limited work on temporal changes in functional diversity in response to major disturbances (Mouillot et al., 2012). Instead, recent work has focused on spatial differences in functional diversity between areas of disturbed and undisturbed habitat (e.g. Gerisch et al., 2012; Hidasi-Neto et al., 2012). Moreover, there are few investigations documenting temporal changes in functional diversity in concert with temporal changes in landscape cover or habitat structure. In addition, whilst many studies compare different aspects of the distribution of traits among species (i.e. functional richness: 
the amount of occupied trait space), it appears that few metrics are able to quantify shifts in the distribution of traits as functional composition changes (i.e. where the occupied trait spaces occurs) (but see Mouillot et al., 2012).

Conceptual and empirical work has proposed the "performance filtering hypothesis" (Mouillot et al., 2012; Barnagaud et al., 2014) based on evidence that species with some functional traits will respond less favourably than others in landscapes undergoing change (e.g. Henle et al., 2004; Lindenmayer \& Fischer 2006; Newbold et al., 2013). More recently, conceptual models of biotic responses to landscape transformations (see Watson et al., 2014), suggest that generalist species can be gained at the expense of specialist species. In such cases, responses can be expected to have impacts on the amount of trait space occupied due to the changes in species representation (Schleuter et al., 2010; Mouillot et al., 2012). In contrast, a recent study of co-occurrence of a small set of bird guilds (Lindenmayer et al., 2014) provides evidence for the replacement of species with functionally-similar species within the same guild following landscape transformation. Under this model, the amount and location of occupied trait space may change little, despite changes in species composition. Further, depending on how landscape transformation acts on community assembly processes, such as environmental filtering and competitive exclusion, different trajectories of species richness change may accompany changes in functional diversity (Mayfield et al., 2010). Consistent with the "sampling effect hypothesis" (Srivastava \& Vellend 2005), change in functional diversity may be positively correlated with species richness change; alternatively community-turnover may lead to changes in functional diversity with species richness remaining constant (Mayfield et al., 2010). The latter is supported by a recent global analysis of time series data (see Dornelas et al., 2014), which found that despite substantial changes in landscape cover, species richness remains largely unchanged over time. 
In this paper, we quantify long-term bird assemblage responses to major landscape transformation resulting from large-scale plantation expansion. This has occurred in a semicleared former grazing ecosystem where an array of patches of woodland initially surrounded by cleared farmland are now embedded in a landscape dominated by stands of exotic Radiata Pine (Pinus radiata). We quantify temporal changes in bird species richness, assemblage composition and functional diversity using a 15 year large-scale 'natural experiment'. To guide our study, we addressed the following questions:

Question 1. Have there been changes in the amount of trait space occupied and where that occupied trait space occurs in response to changes in landscape cover surrounding the woodland patches in our experiment?

In examining temporal changes in functional diversity measures and some of their inherent characteristics, we explored the influence that selected factors may have in determining these changes. We postulated that time since plantation establishment and the size of remnant woodland patches would have important effects on the amount and movement of occupied trait space. However, we also explored the influence of other potential explanatory variables like the type of woodland that characterised the native vegetation patches in our study.

Question 2. What changes in overall bird species richness and species-composition of the bird assemblage have accompanied landscape transformation? We postulated that despite substantial changes in landscape cover, species richness would remain largely unchanged over time. We forecast this response because: (1) the woodland patches in our study have remained largely unchanged in size, shape and vegetation condition in the 15 years since the commencement of the study, and, (2) whilst the landscape surrounding the woodland patches has been transformed from farmland to plantation pine, earlier meta-analyses (Felton et al., 2010) have suggested there are few differences in the species richness of most groups of organisms between these two kinds of environments. To examine species richness, we 
explored the influence that selected factors, such as the size of the remnant woodland patch, (e.g. see Rosenzweig 1995; Lindenmayer et al., 2008b) may have in determining the response. We also postulated that there would be large changes in the composition of the bird assemblage resulting from the replacement of open-woodland bird species associated with farmland-dominated environments by closed-forest taxa for which pine plantations can provide a crude proxy for suitable habitat.

The results of our study suggest that important new insights into the impacts of landscape transformation on biodiversity can be obtained when a suite of measures of biotic response - particularly species richness, assemblage composition and functional diversity are examined concurrently (Petchey \& Gaston 2002). However, we also demonstrate how different environmental and disturbance factors can influence several measures of biotic response, and that these need to be considered as part of informed strategies that attempt to "conserve biodiversity" in landscapes undergoing major and rapid transformation.

\section{(A) METHODS \\ (B) Study area}

Our study region is the Nanangroe area, 10-20 km south-east of the town of Jugiong in southern New South Wales, south-eastern Australia (Fig. 1). Nanangroe (coordinates $34.9^{\circ}$ $35.0^{\circ} \mathrm{S}$ and $148.4^{\circ}-148.5^{\circ} \mathrm{E}$, altitudinal range: $250-750 \mathrm{~m}$ above sea level) is characterised by a temperate climate (hot summers and relatively cool winters). The original vegetation cover included temperate woodland vegetation types, dominated by Eucalyptus species. In Australia, forests and woodlands are classified as markedly structurally and compositionally different kinds of vegetation, with the former being taller, more densely stocked environments, often characterised by midstorey, understorey and ground layers (Specht \& Specht 1999). 
Over $80 \%$ of the native temperate woodland vegetation cover in our study area has been cleared in the past 150 years, primarily for sheep and cattle grazing (McKernan 2010). Vegetation in these cleared paddocks is dominated by exotic pasture grasses and isolated single eucalypt trees that are the remnants of past woodland vegetation cover. Prolonged periods of livestock grazing meant that understorey vegetation was largely absent from all areas of woodland in the study area. In several parts of the region, an emerging exotic Radiata Pine plantation now surrounds patches of remnant woodland that escaped earlier waves of land clearing. Further details of the study area can be found in Lindenmayer et al. (2008a).

\section{(B) The design of the Nanangroe study}

In the mid-1990s, the then State Forests of New South Wales began developing plans to convert the Nanangroe property from a grazing enterprise to a plantation-dominated landscape for the production of Radiata Pine timber and paper products. Initially, the entire landscape was to be cleared of all native vegetation. However, discussions between one of the authors (Lindenmayer) and representatives of the former Department of Land and Water Conservation as well as staff from State Forests of New South Wales resulted in all patches of remnant temperate eucalypt woodland in the Nanangroe region being excluded from clearing. In 1998, prior to commencement of landscape transformation to a pine-dominated system, we randomly selected 55 of the 70 remnant woodland patches, stratified by vegetation class and woodland patch size. The 55 woodland patches were exempt from clearing while plantation establishment was undertaken in the surrounding areas. The patches varied in dominant vegetation type, including Yellow Box (Eucalyptus melliodora), Red Box

(E. polyanthemos), White Box (E. albens), Blakely's Red Gum (E. blakelyi), Apple Box (E. bridgesiana) and Long-leaf Box (E. goniocalyx). In addition, there were patches dominated by Red Stringybark (E. macrorhyncha), Broad-leaved Peppermint (E. dives), and River Oak (Allocasuarina cunninghamiana). 
The size of the temperate woodland patches ranged from 0.5 to 28.8 ha (median $=1.5$ ha, 32 remnants $<2$ ha). Although our investigation included some larger remnant patches (e.g. eight $>5$ ha), numerous large woodland patches were not available for study because of the extent of past land clearing for agriculture and domestic livestock grazing in this part of Australia (McKernan 2010). The average distance between sites was $7.4 \mathrm{~km}$, with $90 \%$ of sites more than 800 metres apart. Careful examination of our data indicated no substantial, systematic spatial dependence among the sites in our dataset.

Between 1997 and 2013, grazing by domestic livestock continued throughout the pine plantations and the 55 patches of remnant woodland at Nanangroe. This was important to ensure that grazing and landscape context effects were not confounded.

The Radiata Pine plantations at Nanangroe are subject to a range of silvicultural treatments over the duration of the approximately 30-year logging rotation. Approximately 12-15 years after plantation establishment, stands are thinned. Thinning is planned to be repeated when stands reach $22-25$ years before a final clearfell logging operation at approximately 30 years after stand establishment (Lindenmayer 2009).

\section{(B) Bird surveys}

Australian temperate woodlands are species-rich environments, with detailed studies showing they support in excess of 150 native species of birds, but very few exotic species (Cunningham et al., 2014). These species vary in body mass from 6 grams to $6.5 \mathrm{~kg}$ and are characterised by marked differences in key life history attributes such as foraging guild, nesting type, social system and movement behaviour (e.g. resident to altitudinal or latitudinal migrant).

To survey birds, we established a permanent $200 \mathrm{~m}$ long transect randomly within each of the 55 woodland patches. For each survey, two observers each visited three points at $0 \mathrm{~m}$, $100 \mathrm{~m}$ and $200 \mathrm{~m}$ along the transect on different days; typically 2-4 days apart. At each point, 
the observer recorded which species were detected in a 5 minute interval and within $50 \mathrm{~m}$ of the point. We completed field surveys in early November of 1999, 2001, 2003, 2005, 2007, 2009, 2011 and 2013. Early November is the peak breeding season in the study region, when summer migrants are present and birds have established territories and exhibit strong patterns of site fidelity (Lindenmayer et al., 2008a). Detections were made between 5.30-9.30 a.m. and were not undertaken on days of poor weather (rain, high wind, fog or heavy cloud cover). The order in which particular sites were surveyed on any given day was varied so that if birds were sampled, for example, late in the morning on a site on one day, that site was surveyed early in a subsequent survey.

Highly experienced bird observers completed surveys of forest and woodland birds. These observers varied in their ability to detect some groups of birds but Lindenmayer et al. (2009) showed that pooling counts of two or more observers at the same plot point could compensate for extra variability due to observer heterogeneity.

\section{(B) Bird traits and life history attributes}

Many studies have shown that avian responses to disturbance can be linked with life history attributes (e.g. Hansen \& Urban 1992; Brawn et al., 2001; Sodhi et al., 2004; Haddad et al., 2008). Given this, we collated data from the literature on life history and other attributes for each bird species (Handbook of Australian and New Zealand Birds 1990-2007; BirdLife Australia 2014). We summarized data on life history (habitat, diet, foraging substrate, social system, reproductive effort and migratory status), and morphological traits (body mass and wing morphology) (see Appendix S1 in Supporting Information). These traits are thought to reflect the ability of species to respond to environmental change (Luck et al., 2012).

\section{(A) STATISTICAL ANALYSIS}


We examined a variety of responses associated with functional diversity using statistical modelling and Principal Co-ordinate Analysis (PCoA) (Venables \& Ripley 2002) to explore how bird communities were changing over time.

We calculated three functional diversity measures: (1) functional richness, (2) functional evenness, and (3) functional dispersion. Functional richness represents the amount of functional space filled by the community (i.e. the volume of the multidimensional trait space, also known as the convex hull), functional evenness describes the evenness of the abundance distribution in functional trait space, and functional dispersion is the mean distance of individual species to the centroid of all species in the community (sensu Laliberte \& Legendre 2010). For these analyses, we used the eight bird traits and presence/absence survey data. We calculated our functional diversity metrics using the Gower dissimilarity measure (Legendre \& Legendre 2012) in the 'FD' package (Laliberte \& Legendre 2010; Laliberte \& Shipley 2011) using the R statistical program(R Core Development Team 2014). We weighted categorical traits by the reciprocal of the number of classes within each trait.

We obtained an estimate of species richness from our survey data, where presence was scored if a species was detected from at least one of the six survey occasions conducted over the two day survey period. We did not adjust for detection (Gotelli \& Chao 2013) given that: (1) sampling effort was constant and we expected bias to be similar among patches and (2) there are significant issues outlined with its application in this study system (see Welsh et al., 2013).

We used linear and generalised linear mixed models to explore relationships between assemblage diversity measures and the following covariates: time since planting, patch size $\left(\log _{10}\right)$, number of woodland patch boundaries surrounded by plantation, and vegetation type. For the modelling, we accommodated the tendency for repeat observations within sites to be more similar than observations across sites through the inclusion of random effects for each 
site. We explored non-linearity in the responses and temporal dependence of within-site errors using smoothed terms and a first-order autoregressive correlation structure for the errors (AR(1)), respectively. We used Bayesian (Schwarz) information criteria (BIC) to guide model selection and we examined residuals and predicted random effects as part of model diagnostics.

To quantify temporal changes in functional diversity, we used statistical modelling to examine what factors influenced the shift in relative position of the functional richness trait space representation. We did this by quantifying what factors influenced: (a) the movement of the functional richness convex hull centroid (i.e. the centroid of the volume of trait space occupied by species), and (b) the overlap (intersection/union) of the area of the convex hull between successive field surveys. We constructed our functional richness convex hull from two PCoA coordinate axes. The motivation for exploring the influences behind the position of the species in trait space was the circumstance where the magnitude of the representation may not change substantially (i.e. no difference in functional richness), but the location of the convex hull may change (equivalent to a displacement of the centroid), reflecting a realignment of the traits of species being recorded while at the same time maintaining the breadth of functional trait representation.

To examine species composition we used a second PCoA ordination using the Gower dissimilarity measure of survey sites in species space to explore how species composition may be changing over time with the maturation of the pine plantation surrounding the woodland patches. Using a two-axis representation of the ordination, we modelled the movement of axis- 1 and axis- 2 coordinates over time in a similar fashion to the centroids of the functional richness convex hull (above) using the following explanatory variables: time since planting, patch size $(\log )$,number of sides surrounded by plantation, and vegetation type. 


\section{(A) RESULTS}

Survey data from 85 bird species representing 30 families were used in the study (Appendix S2). The number of species recorded at a site over the duration of the study ranged from 30 to 58 (mean of 46). Approximately $70 \%$ of the species typically rely on forested habitat, with the remaining more closely associated with open-woodland habitat. Four dietary groups were identified for this study: approximately $50 \%$ of the species were insectivorous with the remaining taxa distributed among nectarivorous and granivorous guilds as well as those species having a more omnivorous diet.

\section{(B) Functional diversity and species richness}

The functional diversity measures for the individual sites commonly displayed a pattern of substantial variation over time but we found no evidence of non-linearity in the responses. The functional diversity measures were strongly associated with 'time since planting' (Table 1, Appendix S3A). However, this was not the case for species richness, for which the only significant explanatory variable we identified was a positive relationship with $\log$ patch size $(\mathrm{p}<0.001)$. For the functional richness measure, we identified two models with similarly low BIC values, both of which provided evidence for decreasing mean functional richness with time since planting $(\mathrm{p}<0.001)$. In addition, we found some evidence for lower mean functional richness in native woodland patches that were enclosed on all four

sides by maturing stands of Radiata Pine plantation, rather than having three or fewer sides of pine adjacent to the woodland patch $(\mathrm{p}=0.02)$. Both of these models for functional richness had similar coefficient estimates for the time since planting term (Table 1). For functional evenness and functional dispersion, we found evidence for a decreasing mean value with time since planting $(\mathrm{p}<0.001$ and $\mathrm{p}<0.001$, respectively).

\section{(B) A closer look at functional richness}


We constructed our functional richness convex hull from two PCoA coordinate axes. Examining the relationships between the values of the two coordinate axes and the original traits revealed a contrast along the first axis between birds that primarily inhabit forest environments versus those typical of more open environments such as semi-cleared woodlands and pastures (Fig. 2). An additional contrast that axis 1 displayed was between insectivorous and/or nectarivorous species and taxa characterised by other kinds of diets. The second axis suggested a contrast between birds with different social systems - those more likely to occur in flocks versus species which typically live in pairs or are solitary (Fig. 2). The other traits did not contribute strongly to the ordination.

We also sought to determine how the location of trait space changed over time using the centroid of the convex hull of the trait space. We modelled each centroid coordinate independently and found strong evidence of increasing mean axis-1 value with time since planting $(\mathrm{p}<0.001)$, as well as evidence for slightly greater mean axis-1 values in woodland patches with all four sides surrounded by adjacent Radiata Pine compared to woodland patches that had three or less sides with adjacent pine ( $p=0.05$; Table 2, Appendix S3B).

For the second axis co-ordinate value of the convex hull centroid, we found evidence of a decreasing mean value with time since planting $(\mathrm{p}<0.001)$ and a reduced mean value for patches surrounded on all four sides by stands of Radiata Pine plantation $(p=0.03)$. These convex hull results, from each of the two axes considered together, correspond to movement in the mean centroid of the functional richness convex hull to the 'south-east' of the trait space as stands of Radiata Pine surrounding our woodland patches matured over time (Fig. 3, Appendix S4). We found that those woodland remnants surrounded by Radiata Pine stands on all four sides had, on average, centroids further to the 'south-east' of the trait space than those woodland patches surrounded by pine stands on three or fewer sides. 
We found evidence of decreasing mean intersection and decreasing mean union of overlap in area of convex hulls with time since planting $(\mathrm{p}<0.001$ and $\mathrm{p}<0.001$, respectively) (Table 3; Fig. 4; Appendix S3C). That is, the average area occupied by the convex hulls derived from each of two successive years of surveys (i.e. their union) decreased over time, as did the area of overlap (intersection) between the two convex hulls from each of two successive years of surveys. There also was evidence of increasing mean union of successive convex hulls with increasing $\log$ patch size $(\mathrm{p}=0.008)$. For the ratio of the two values - intersection/union — which is the amount of trait space that successive survey results shared as a fraction of the total area the surveys both occupied, we found no significant effects from the covariates.

\section{(B) Species composition}

To complement our analyses of functional diversity measures, we examined species composition using a PCoA ordination of survey sites. That is, we used a site ordination in 'species space' to explore how the bird community may be changing. We modelled the coordinates independently of each other and found strong evidence of mean decreasing axis-1 values with increasing time since planting ( $p<0.001$; Fig. 5; Appendix S5) and reduced mean axis-1 values for those woodland remnants surrounded by Radiata Pine stands on all four sides $(\mathrm{p}<0.001$; Table 4$)$. Species 'variables' projected on to the sites in the species space ordination provides information on those species that will tend to be increasingly and decreasingly recorded over successive surveys as the stands of Radiata Pine surrounding the woodland matured. A right-to-left movement of a survey site co-ordinate in species space suggested that species on the right-hand side of the ordination were recorded less frequently over time, e.g. White-plumed Honeyeater (Lichenostomus penicillatus), Willie Wagtail (Rhipidura leucophrys) and Red Wattlebird (Anthochaera carunculata). Conversely, species on the left-hand side were more frequently recorded over time as the pine plantation matured, 
e.g. White-browed Scrubwren (Sericornis frontalis), Brown Thornbill (Acanthiza pusilla) and Grey Fantail (R. albiscapa) (Fig. 6).

Modelling of the axis- 2 coordinate provided strong evidence of decreasing mean axis2 values with increasing log patch size $(\mathrm{p}=0.0014)$. This indicated that species such as the White-throated Gerygone (Gerygone olivacea), Striated Pardalote (Pardalotus striatus), Buff-rumped Thornbill (A. reguloides) and the White-throated Treecreeper (Cormobates leucophaea) may be more commonly found in the larger patches of remnant woodland. We acknowledge the need for caution in modelling and presenting results from the first two ordination axes as the first two dimensions account for $<20 \%$ of variation in the dissimilarities between the sites.

\section{(A) DISCUSSION}

Few studies have examined changes in functional diversity over both prolonged periods and in response to major disturbance such as the substantial changes in resources and conditions associated with the establishment of Radiata Pine plantations. To address this knowledge gap, we completed a large-scale and long-term study of measures of functional richness for birds in a region subject to major landscape transformation where woodland patches remained unchanged but the surrounding landscape context has been massively altered by exotic plantation establishment. We found strong evidence for reductions in functional diversity over time since the establishment of stands of Radiata Pine in the areas surrounding the woodland patches. Consistent with the "performance filtering hypothesis" (Mouillot et al., 2012; Barnagaud et al., 2014), we found reduced overlap in the amount of trait space that was occupied by sets of species between successive years. The temporal reduction in trait space was linked to a shift away from solitary or pair-forming species characteristic of openwoodland environments and which consumed seeds and various other food resources to insectivorous and nectarivorous, forest-associated taxa that typically occur in flocks or 
groups. These effects were strongest in woodland patches surrounded by Radiata Pine plantations on all four sides than in those patches characterised by one or more sides adjacent to agricultural land where pine stands had not been established. We also found evidence of species turnover, with no change in species richness over time (with woodland patch size being the only significant effect for this measure) but marked temporal change in the composition of the bird community. This was reflected by changes from open-woodland species to forest-associated species - broadly consistent with the results from our analyses of functional diversity. We further discuss these and other findings in the remainder of this paper. We also outline how our study revealed major changes in the bird assemblages over time, but a suite of measures, including those associated with species richness, functional diversity, and assemblage composition was required to provide a broader picture of biotic responses to major landscape transformation.

\section{(B) Temporal changes in species richness and functional diversity}

We observed no significant change in bird species richness over time, despite major changes in the type of cover (growth of exotic stands of Radiata Pine) that dominated our study area. This finding was broadly consistent with a recent meta-analysis of an array of time series datasets which showed no loss in species richness but major changes in composition following landscape change (Dornelas et al., 2014). Indeed, the only factor which influenced species richness was the size of woodland patches embedded within the pine plantation - an expected outcome based on well-established species-area relationships (reviewed by Rosenzweig 1995)).

In contrast with our results for species richness, we found significant temporal changes in functional diversity. The most substantial declines in functional richness occurred in woodland patches surrounded by long established stands of Radiata Pine. Indeed, plantation age affected most functional diversity measures that we tested. We suggest that the 
longer new (plantation pine) environments have been established, the greater their effects will be on adjacent woodland patches, through mechanisms such as: (1) attracting new (typically closed forest-associated) species to the region which then spill over into neighbouring woodland patches, and/or (2) changing available food resources such as insects, nectar and seeds - as suggested by life history trait patterns in our analyses.

We observed the greatest declines in functional richness in woodland patches completely surrounded by pine plantations (i.e. in patches where there were no boundaries with agricultural land). The reasons for the boundary effects on functional trait space in our study remain unclear. It is possible that open-woodland birds cannot move through, find, colonize or use woodland patches when they are completely surrounded by Radiata Pine (Mortelliti and Lindenmayer, submitted), with stands of exotic plantation trees acting as a kind of barrier effect for these species. In contrast, such effects were less pronounced in those woodland patches that shared one or more boundaries with agricultural land where openwoodland bird species can be common. This, in turn, may have enabled open-woodland birds continued access to those woodland patches not entirely surrounded by stands of Radiata Pine. Earlier studies have identified relationships between edge environments and bird functional diversity (Barbaro et al., 2013). However, the mechanisms and environments in those previous investigations are somewhat different to those in the plantation-dominated environments characterising the work reported here.

An important innovation in our study was the closer examination of the functional richness convex hull, which defines the magnitude of this diversity measure. We examined the centroids and hull overlap to quantify changes in the size, location and overlap of trait space over time. We suggest that this approach can help explore core ecological processes such as successional trajectories in recovery from, or response to, disturbance. For example, our analyses exploring movement of the convex hulls revealed that not only was there a 
temporal reduction in the amount of occupied trait space (i.e. the observed reduction in functional richness), but the average position of that trait space changed over time. In addition, the amount of trait space overlapping between successive years declined. Allied with this temporal divergence in the amount and location of trait space was the indication that this was occurring because of a loss of open- woodland birds as well as species which consumed food other than insects or nectar and occurred in pairs or as solitary individuals. Thus, our analyses revealed the kinds of life history traits likely to be lost with landscape transformation involving maturation of stands of plantation trees. Hence, our empirical work contains evidence to support the "performance filtering hypothesis" (Mouillot et al., 2012; Barnagaud et al., 2014) in which species with some functional traits are prone to decline in landscapes undergoing change (Henle et al., 2004; Lindenmayer \& Fischer 2006; Newbold et al., 2013). Examination of the composition of the bird assemblage (Figs. 5 and 6) indicated which species were those likely to be lost or gained as a result of the maturation of the pine plantation (see below).

\section{(B) Temporal changes in the composition of the bird assemblage}

Our data indicated there have been marked changes in the composition of the bird assemblage over time. These findings, coupled with the lack of change in species richness, suggest that species replacements must be occurring. A potential mechanism for these replacements would be competitive interactions such as within-guild replacements of species which share similar traits (Fig. 6). As an example, open-woodland species such as Whiteplumed Honeyeater, which was abundant at the start of our experiment, appears to have been largely replaced by the forest-associated Yellow-faced Honeyeater (L. chrysops), which was initially uncommon. Recent intra-guild co-occurrence analyses suggest that has happened within some but all not bird guilds (Lindenmayer et al., 2014). 
Our work suggests that different factors influenced different metrics such as species richness and functional diversity. We found that different factors were important predictors of different functional response measures, although plantation age affected most functional diversity measures that we examined. This highlights the need for care about the kinds of recommendations made for managing "biodiversity" in ecosystems subject to environmental change. Indeed, if the sole measure of biotic response was species richness, then no recommendations for altered management would be made for this study because species richness remained largely unchanged over time. However, measures of functional diversity suggest a need to consider the effects of factors like the time since plantation establishment and the number of woodland patch edges with the surrounding plantation. For example, if a management objective is to maintain taxa typical of open environments within the woodland patches located within an otherwise plantation-dominated landscape (as occurs in other jurisdictions elsewhere around the world (Peterken 1996)), then a directive might be to ensure those patches are not completely surrounded by stands of exotic Radiata Pine.

\section{(B) The value of multiple measures of biotic response to landscape transformation}

Our study identified only limited change in overall bird species richness but large changes in the composition of the bird assemblage. Thus, particular species have been replaced by others and our functional diversity data indicated that the functional roles of these different species (as reflected by the amount of trait space that is filled) has changed concurrent with the temporal changes in the composition of the bird community (see Figure 7). Functional diversity data have therefore added extra insights into the biotic changes associated with landscape transformation. That is, more knowledge is gained by examining a suite of measures of the biota (here species richness, assemblage composition and functional diversity) than any one individually (Petchey \& Gaston 2002; McGill et al., 2006; Weiher et al., 2011). 


\section{(A) ACKNOWLEDGMENTS}

We thank various organisations for funding the work in the Nanangroe Experiment over the past 17 years. These include the Australian Research Council, the National Environmental Research Program, and the Long-term Ecological Research Network (LTERN) with the Terrestrial Ecosystem Research Network (TERN).

\section{(A) BIOSKETCH}

(B) General statement of focus of research team: The team specialises in large-scale, longterm empirical research in production landscapes and conservation areas, with an emphasis on biodiversity responses to landscape change and management interventions. The research team includes expert statistical scientists, field-based ecologists dedicated to gathering high quality field data, and ecologists with particular expertise in theory.

(B) Statement of author roles: All authors conceived and designed the study; DL, SO, MC and DM gathered the field data; WB and PT completed the detailed statistical analysis; all authors contributed to the writing, which was led by DL.

\section{(A) REFERENCES}

Barbaro, L., Giffard, B., Charbonnier, Y., van Halder, I. \& Brockerhoff, E.G. (2013) Bird functional diversity enhances insectivory at forest edges: a transcontinental experiment. Diversity and Distributions, 20, 149-159.

Barnagaud, J.-V., Barbaro, L., Papaïx, J., Deconchat, M. \& Brockerhoff, E.G. (2014) Habitat filtering by landscape and local forest composition in native and exotic New Zealand birds. Ecology, 95, 78-87.

BirdLife Australia (2014) Birds in Backyards Bird Finder. Available at http://www.birdsinbackyards.net/finder/all-species.

Brawn, J.R.D., Robinson, S.K. \& Thompson, F.R. (2001) The role of disturbance in the ecology and conservation of birds. Annual Review of Ecology and Systematics, 32, 251-276. 
Cadotte, M.W., Carscadden, K. \& Mirotchnick, N. (2011) Beyond species: functional diversity and the maintenance of ecological processes and services. Journal of Applied Ecology, 48, 1079-1087.

Cunningham, R.B., Lindenmayer, D.B., Barton, P., Ikin, K., Crane, M., Michael, D., Okada, S., Gibbons, P. \& Stein, J. (2014) Cross-sectional and temporal relationships between bird occupancy and vegetation cover at multiple spatial scales. Ecological Applications, 24, 12751288.

Dornelas, M., Gotelli, N.J., McGill, B., Shimadzu, H., Maues, F., Sievers, C. \& Magurran, A.E. (2014) Assemblage time series reveal biodiversity change but not systematic loss. Science, 344, 296-299.

Felton, A., Knight, E.J., Wood, J.T., Zammit, C. \& Lindenmayer, D.B. (2010) A metaanalysis of fauna and flora species richness and abundance in plantations and pasture lands. Biological Conservation, 143, 545-554.

Forman, R.T. (2014) Urban Ecology. Cambridge University Press. Cambridge, England. Gerisch, M., Agostinelli, V., Henle, K. \& Dziock, F. (2012) More species, but all do the same: contrasting effects of flood disturbance on ground beetle functional and species diversity. Oikos, 121, 508-515.

Gotelli, N.J. \& Chao, A. (2013) Measuring and estimating species richness, species diversity, and biotic similarity from sampling data. Encyclopedia of Biodiversity, 2nd edition. (ed. by S.A. Levin), pp. 195-211. Academic Press, Waltham, Massachuseets.

Haddad, N.M., Holyoak, M., Mata, T.M., Davies, K.F., Melbourne, B.A. \& Preston, K. (2008) Species' traits predict the effects of disturbance and productivity on diversity. Ecology Letters, 11, 348-356.

Handbook of Australian and New Zealand Birds (1990-2007) Handbook of Australian, New Zealand and Antarctic Birds, Volumes 1-7. Oxford University Press. Melbourne. 
Hansen, A.J. \& Urban, D.L. (1992) Avian response to landscape pattern: the role of species' life histories. Landscape Ecology, 7, 163-180.

Hanspach, J., Fischer, J., Ikin, K., J., S. \& Law, B.S. (2012) Using trait-based filtering as a predictive framework for conservation: a case study of bats on farms in southeastern Australia. Journal of Applied Ecology, 49, 842-850.

Henle, K., Davies, K., Kleyer, M., Margules, C. \& Settele, J. (2004) Predictors of sensitivity to fragmentation. Biodiversity and Conservation, 13, 207-215.

Hidasi-Neto, J., Barlow, J. \& Cianciaruso, M.V. (2012) Bird functional diversity and wildfires in the Amazon: the role of forest structure. Animal Conservation, 15, 407-415. Kremen, C., Williams, N.M., Aizen, M.A., Gemmill-Heren, B., LeBuhn, G., Minckley, R., Packer, L., Potts, S.G., Roulston, T., Steffan-Dewenter, I., Vazquez, D.P., Winfree, R., Adams, L., Crone, E.E., Greenleaf, S.S., Keitt, T.H., Klein, A.M., Regetz, J. \& Rickett, T.H. (2007) Pollination and other ecosystem services produced by mobile organisms: a conceptual framework for the effects of land-use change. Ecology Letters, 10, 299-314.

Laliberte, E. \& Legendre, P. (2010) A distance-based framework for measuring functional diversity from multiple traits. Ecology, 91, 299-305.

Laliberte, E. \& Shipley, B. (2011) FD: measuring functional diversity from multiple traits, and other tools for functional ecology.

Lavorel, S. \& Garnier, E. (2002) Predicting changes in community composition and ecosystem functioning from plant traits: revisiting the Holy Grail. Functional Ecology, 16, $545-556$.

Legendre, P. \& Legendre, L. (2012) Numerical Ecology. Elsevier. Amsterdam. Lindenmayer, D.B. (2009) Large-Scale Landscape Experiments. Lessons from Tumut. Cambridge University Press. Cambridge. 
Lindenmayer, D.B., Cunningham, R.B., McGregor, C., Crane, M., Michael, D., MontagueDrake, R., Fischer, J., Felton, A. \& Manning, A. (2008a) Temporal changes in vertebrates during landscape transformation: a large-scale "natural experiment". Ecological Monographs, 78, 567-590.

Lindenmayer, D.B. \& Fischer, J. (2006) Habitat Fragmentation and Landscape Change. Island Press. Washington, D.C.

Lindenmayer, D.B., Hobbs, R., Montague-Drake, R., Alexandra, J., Bennett, A., Burgman, M., Cale, P., Calhoun, A., Cramer, V., Cullen, P., Driscoll, D., Fahrig, L., Fischer, J., Franklin, J., Haila, Y., Hunter, M., Gibbons, P., Lake, S., Luck, G., MacGregor, C., McIntyre, S., Mac Nally, R., Manning, A., Miller, J., Mooney, H., Noss, R., Possingham, H., Saunders, D., Schmiegelow, F., Scott, M., Simberloff, D., Sisk, T., Tablr, G., Walker, B., Wiens, J., Woinarski, J. \& Zavaleta, E. (2008b) A checklist for ecological management of landscapes for conservation. Ecology Letters, 11, 78-91.

Lindenmayer, D.B., Welsh, A., Blanchard, W., Tennant, P. \& Donnelly, C.F. (2014) Exploring co-occurrence of closely-related guild members in a fragmented landscape subject to rapid transformation. Ecography, 37, 1-10.

Lindenmayer, D.B., Wood, J.T. \& MacGregor, C. (2009) Do observer differences in bird detection affect inferences from large-scale ecological studies? Emu, 109, 100-106. Luck, G., Lavorel, S., McIntyre, S. \& Lumb, K. (2012) Improving the application of vertebrate trait-based frameworks to the study of ecosystem services. Journal of Animal Ecology, 81, 1065-1076.

Mayfield, M.M., Bonser, S.P., Morgan, J.W., Aubin, I., McNamara, S. \& Vesk, P.A. (2010) What does species richness tell us about functional trait diversity? Predictions and evidence for responses of species and functional trait diversity to land-use change. Global Ecology and Biogeography, 19, 423-431. 
McGill, B., Enquist, B.J., Weiher, E. \& Westoby, M. (2006) Rebuilding community ecology from functional traits. Trends in Ecology \& Evolution, 21, 178-185.

McKernan, M. (2010) The Valley. A Story from the Heart of the Land. Allen and Unwin. Crows Nest, Australia.

Mouillot, D., Graham, N.A., Villeger, S., Mason, N.W. \& Bellwood, D.R. (2012) A functional approach reveals community responses to disturbances. Trends in Ecology \& Evolution, 28, 167-177.

Newbold, T., Scharlemann, J.P., Butchart, S.H., Sekerciouglu, C.H., Alkemade, R., Booth, H. \& Purves, D.W. (2013) Ecological traits affect the response of tropical bird species to landuse intensity. Proceedings of the Royal Society B, 280, 805-810.

Petchey, O.L. \& Gaston, K.J. (2002) Functional diversity (FD), species richness and community composition. Ecology Letters, 5, 402-411.

Peterken, G.F. (1996) Natural Woodland: Ecology and Conservation in Northern Temperate Regions. Cambridge University Press. Cambridge.

R Core Development Team (2014) R: A Language and Environment for Statistical Computing, Version 3.1.0. R Foundation for Statistical Computing. Vienna, Austria. Rosenzweig, M.L. (1995) Species Diversity in Space and Time. Cambridge University Press. Cambridge.

Schleuter, D., Daufresne, M., Massol, F. \& Argillier, C. (2010) A user's guide to functional diversity indices. Ecological Monographs, 80, 469-484.

Smith, P., Gregory, P.J., van Vuuren, D., Obersteiner, M., Havlik, P., Rounsevell, M., Woods, J., Stehfest, E. \& Bellarby, J. (2010) Competition for land. Philosophical Transactions of the Royal Society B: Biological Sciences 365, 2941-2957.

Sodhi, N.S., Liow, L.-H. \& Bazzaz, F. (2004) Avian extinctions from tropical and subtropical forests. Annual Review of Ecology and Systematics, 35, 323-345. 
Specht, R.L. \& Specht, A. (1999) Australian Plant Communities. Dynamics of Structure, Growth and Biodiversity. Oxford University Press. Melbourne.

Srivastava, D.S. \& Vellend, M. (2005) Biodiversity-Ecosystem Function Research: Is it relevant to conservation? Annual Review of Ecology, Evolution, and Systematics, 36, $267-$ 294.

Tilman, D. (2001) Functional diversity. Encyclopedia of Biodiversity. (ed. by S.A. Levin), pp. 109-120. Academic Press, San Diego, California.

Tscharntke, T., Tylianakis, J.M., Rand, T.A., Didham, R.K., Fahrig, L., Batary, P., Bengtsson, J., Clough, Y., Crist, T.O., Dormann, C.F., Ewers, R.M., Frund, J., R.D., H., Holzschuh, A., Klein, A.M., Kleijn, D., Kremen, C., Landis, D.A., Laurance, W., Lindenmayer, D.B., Scherber, C., Sodhi, N., Steffan-Dewenter, I., Thies, C., van der Putten, W. \& Westphal, C. (2012) Landscape moderation of biodiversity patterns and processes eight hypotheses. Biological Reviews, 87, 661-685.

Venables, W.N. \& Ripley, B.D. (2002) Modern Applied Statistics with S. Springer. New York.

Watson, S.J., Luck, G.W., Spooner, P.G. \& Watson, D.M. (2014) Land-use change: incorporating the frequency, sequence, time span, and magnitude of changes into ecological research. Frontiers in Ecology and the Environment, 12, 241-249.

Weiher, E. (2011) A primer of trait and functional diversity. Biological Diversity: Frontiers in Measurement and Assessment. (ed. by A. Magurran and B. McGill). Oxford University Press, Oxford.

Weiher, E., Freund, D., Bunton, T., Stefanski, A., Lee, T. \& Bentivenga, S. (2011) Advances, challenges and a developing synthesis of ecological community assembly theory. Philosophical Transactions of the Royal Society B: Biological Sciences, 366, 2403-2413. 
Welsh, A.H., Lindenmayer, D.B. \& Donnelly, C.F. (2013) Fitting and interpreting occupancy models. PLOS One, 8, e52015. 


\section{(A) SUPPORTING INFORMATION}

Additional Supporting Information may be found in the online version of this article: Appendix S1 Summary of bird species traits.

Appendix S2 List of species and their acronyms in the study.

Appendix S3A Bayesian (Schwartz) Information Criteria (BIC) values for (generalised) linear mixed models fit to the three functional diversity response measures and species richness.

Appendix S3B Bayesian (Schwartz) Information Criteria (BIC) values for linear mixed models fit to the PCoA axis- 1 and axis- 2 coordinate values for the centroid of the functional richness convex hull.

Appendix S3C Bayesian (Schwartz) Information Criteria (BIC) values for linear mixed models fit to area of intersection, union and their ratio of functional richness convex hulls between successive survey occasions.

Appendix S3D Bayesian (Schwartz) Information Criteria (BIC) values for linear mixed models fit to the PCoA axis- 1 and axis- 2 coordinate values for survey sites in species space. Appendix S4 Study sites showing movement of functional richness convex hull centroids over successive surveys.

Appendix S5 First two axis of 'sites in species space' PCoA ordination reflecting changes in species composition over successive surveys for each site.

As a service to our authors and readers, this journal provides supporting information supplied by the authors. Such materials are peer-reviewed and may be re-organized for online delivery, but are not copy-edited or typeset. Technical support issues arising from supporting information (other than missing files) should be addressed to the authors. 
Table 1. Coefficient estimates corresponding to top-ranked models.

\begin{tabular}{|c|c|c|c|}
\hline & Estimate & SE & $P$-value \\
\hline \multicolumn{4}{|l|}{ Functional Richness } \\
\hline Intercept & 0.18801 & 0.00423 & $<0.001$ \\
\hline Time since planting & -0.00179 & 0.00039 & $<0.001$ \\
\hline \multicolumn{4}{|l|}{ Functional Richness } \\
\hline Intercept (Three Pine sides) & 0.19703 & 0.00555 & $<0.001$ \\
\hline Time since planting & -0.00183 & 0.00039 & $<0.001$ \\
\hline Four sides of Pine & -0.01331 & 0.00554 & 0.02 \\
\hline \multicolumn{4}{|l|}{ Functional Evenness } \\
\hline Intercept & 0.89602 & 0.00275 & $<0.001$ \\
\hline Time since planting & -0.00087 & 0.00025 & $<0.001$ \\
\hline \multicolumn{4}{|l|}{ Functional Dispersion } \\
\hline Intercept & 0.23844 & 0.00295 & $<0.001$ \\
\hline Time since planting & -0.00093 & 0.00024 & $<0.001$ \\
\hline \multicolumn{4}{|l|}{ Species richness } \\
\hline Intercept & 2.68359 & 0.02025 & $<0.001$ \\
\hline Log patch size & 0.08725 & 0.02009 & $<0.001$ \\
\hline
\end{tabular}


Table 2. Coefficient estimates corresponding to movement of the functional richness convex hull centroid along axis-1 and axis-2.

Estimate $\quad$ SE $\quad P$-value

\section{Centroid - Axis-1}

Intercept

0.00496

0.00786

0.528

Time since planting

0.00372

0.00060

$<0.001$

Centroid - Axis-1

Intercept (Three Pine sides)

$-0.00321$

0.00875

0.714

Time since planting

0.00373

0.00060

$<0.001$

Four sides of Pine

0.01241

0.00621

0.051

Centroid - Axis-2

Intercept

Time since planting

Centroid - Axis-2

Intercept (Three Pine sides)

Time since planting

Four sides of Pine
0.00612

$<0.001$

0.00043

$<0.001$
$-0.01439$

$-0.00169$

$-0.01207$

$-0.00169$

$-0.02228$$$
-0.00169
$$

$-0.01207$

$0.00687 \quad 0.037$

$0.00043<0.001$

$0.00532 \quad 0.028$


Table 3. Coefficient estimates corresponding to total area (union) and overlap

(intersection) for sequential pairs of functional richness convex hulls for successive surveys.

$\begin{array}{lll}\text { Estimate } & \text { SE } & P \text {-value }\end{array}$

Union

Intercept

0.23326

0.00476

$<0.001$

Time since planting

$-0.00240$

0.00047

$<0.001$

Union

Intercept

0.22937

0.00491

$<0.001$

Time since planting

$-0.00247$

0.00047

$<0.001$

Log patch size

0.00824

0.00295

0.008

Intersection

Intercept

0.15676

0.00575

$<0.001$

Time since planting

$-0.00185$

0.00055

$<0.001$

Intersection/union

Intercept

0.65856

0.01042

$<0.001$ 
Table 4. Coefficient estimates corresponding to movement of the sites in two-

dimensional species space along axis- 1 and axis-2 of the PCoA ordination.

Estimate $\quad$ SE $\quad P$-value

Sites - Axis-1

Intercept (Three Pine sides)

0.29406

0.03596

$<0.001$

Years since planting

$-0.02907$

0.00189

$<0.001$

Four sides of Pine

$-0.11512$

0.02941

$<0.001$

Sites - Axis-2

Intercept

0.00690

0.02358

0.770

Years since planting

0.00179

0.00185

0.336

Log patch size

$-0.04067$

0.01204

$<0.002$ 


\section{Figure legends}

Fig. 1. Location map of Nanangroe study site

Fig. 2. Relationships between species traits and the values of the functional richness PCoA ordination axes.

Fig. 3. Predicted mean (+- SE) convex hull centroid PCoA axis scores from each time since planting, grouped by number of sides adjoining pine. The predictions (fitted values) were modelled separately with each axis score being the univariate response from a linear mixed model (see Table 2 for coefficient estimates). With the same terms included in each of the two models, the fitted values are displayed jointly here to illustrate the modelled movement of the mean centroid value to the bottom right of the trait space over time.

Fig. 4. The size, position and overlap of functional richness convex hulls between successive surveys for an example site. Here, 1998 is the first survey year and just the one convex hull is illustrated. The next panel for 1999 shows a large amount of overlap (shaded) between the hulls for successive survey occasions 1998 and 1999. The axes represent the PCoA coordinate values from the species in trait ordination.

Fig. 5. Predicted mean (+- SE) species composition PCoA Axis 1 scores for sites from each time since planting, grouped by number of sides adjoining pine (see Table 4 for coefficient estimates).

Fig. 6. Influence of species 'variables' on the PCoA ordination of survey sites. Species labels are provided in Appendix S2. The effect sizes from modelling PCoA Axis-1 (Table 4) are illustrated in the top section of the plot. Since 2009, the mean axis-1 coordinate value for sites grouped by the number of sides adjoining pine are estimated to move from the start to the end of the arrows depicted. 
Figure 1
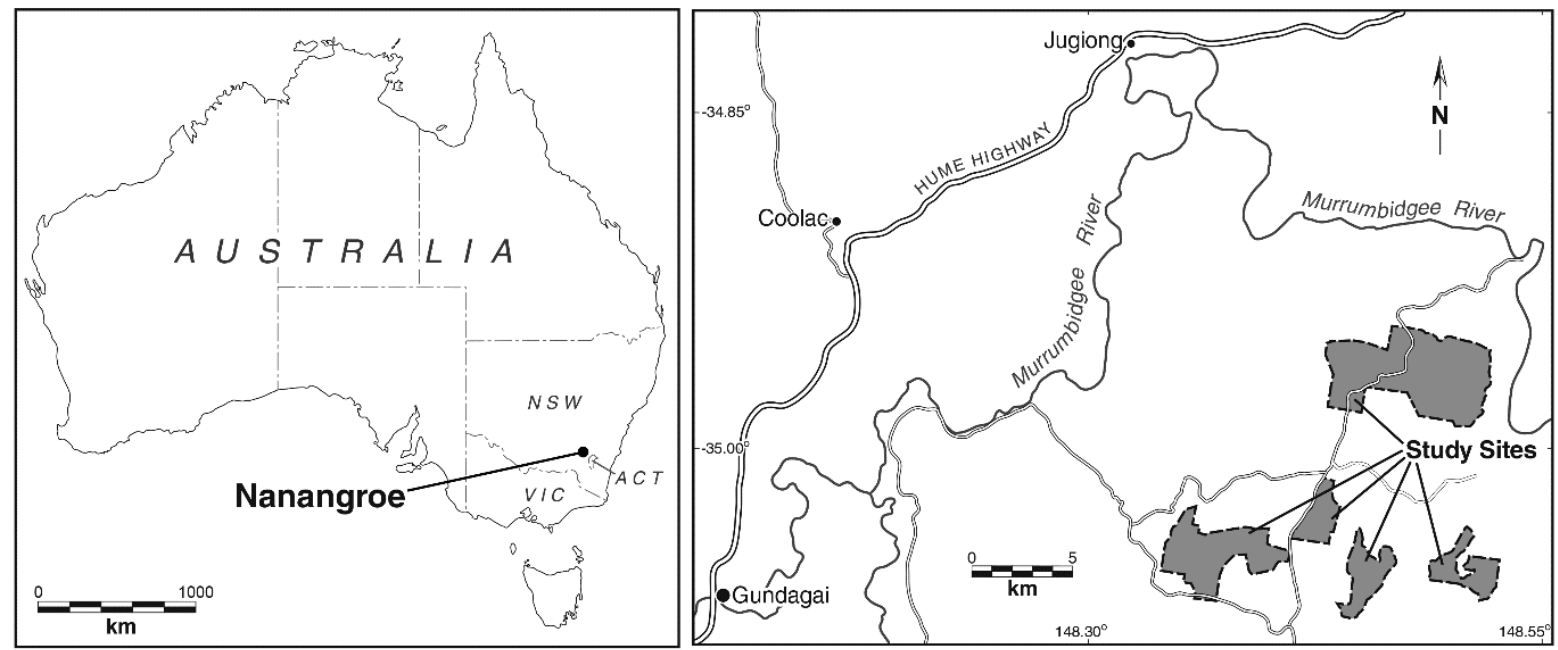
Figure 2
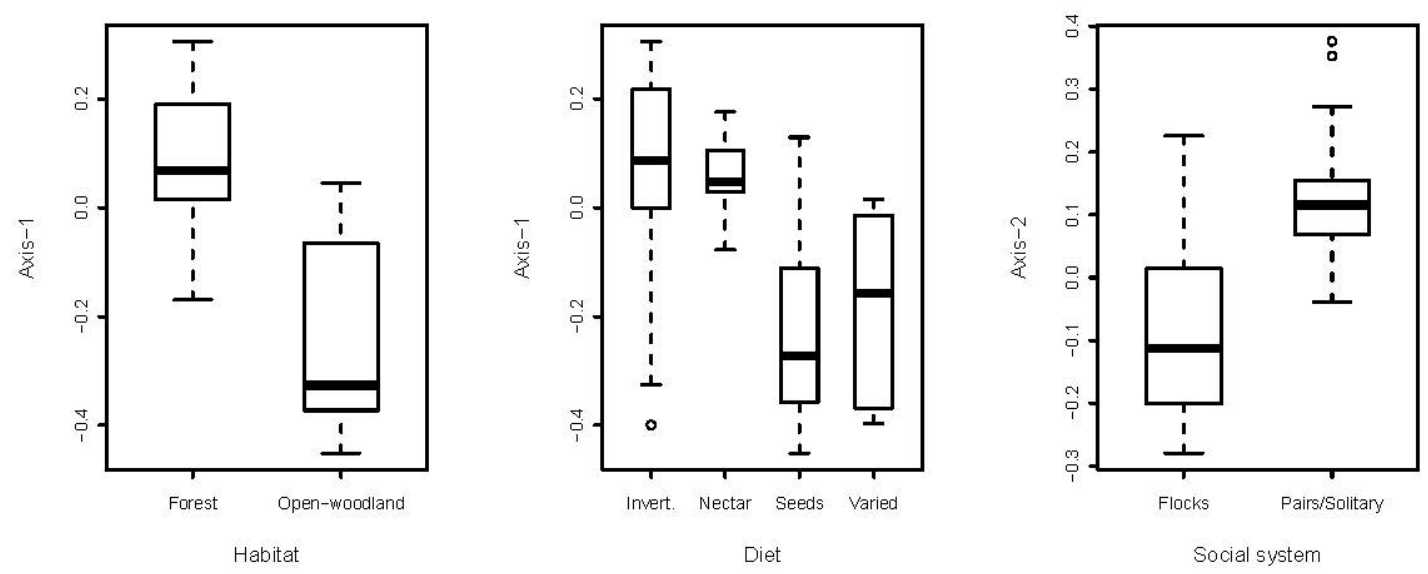
Figure 3

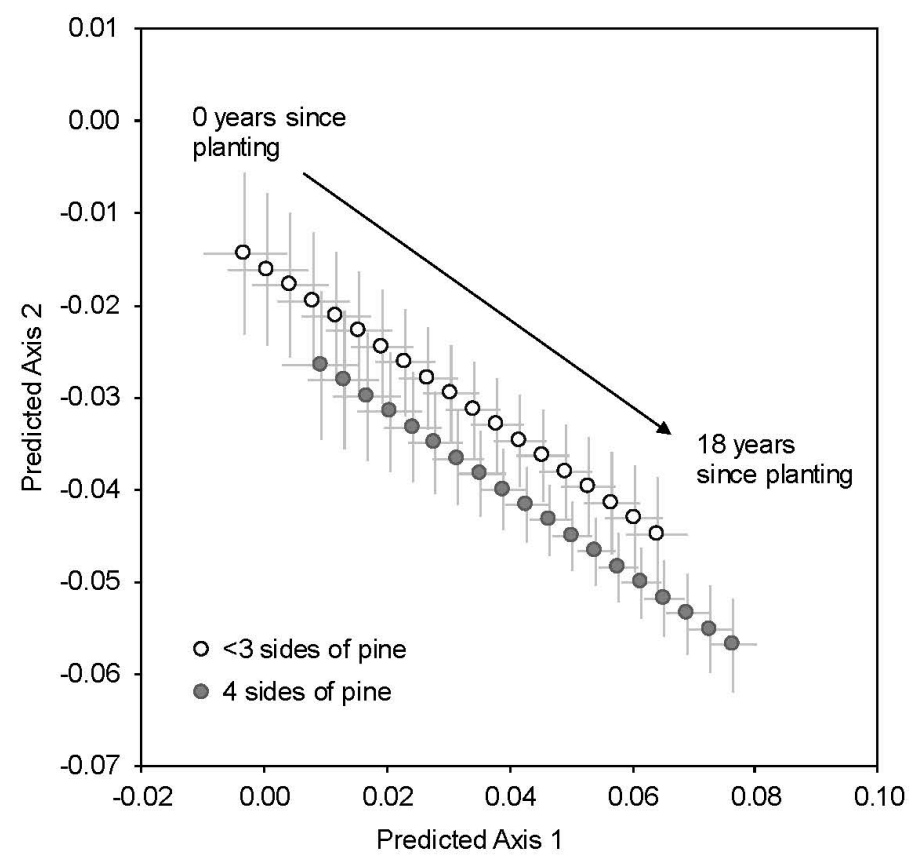


Figure 4
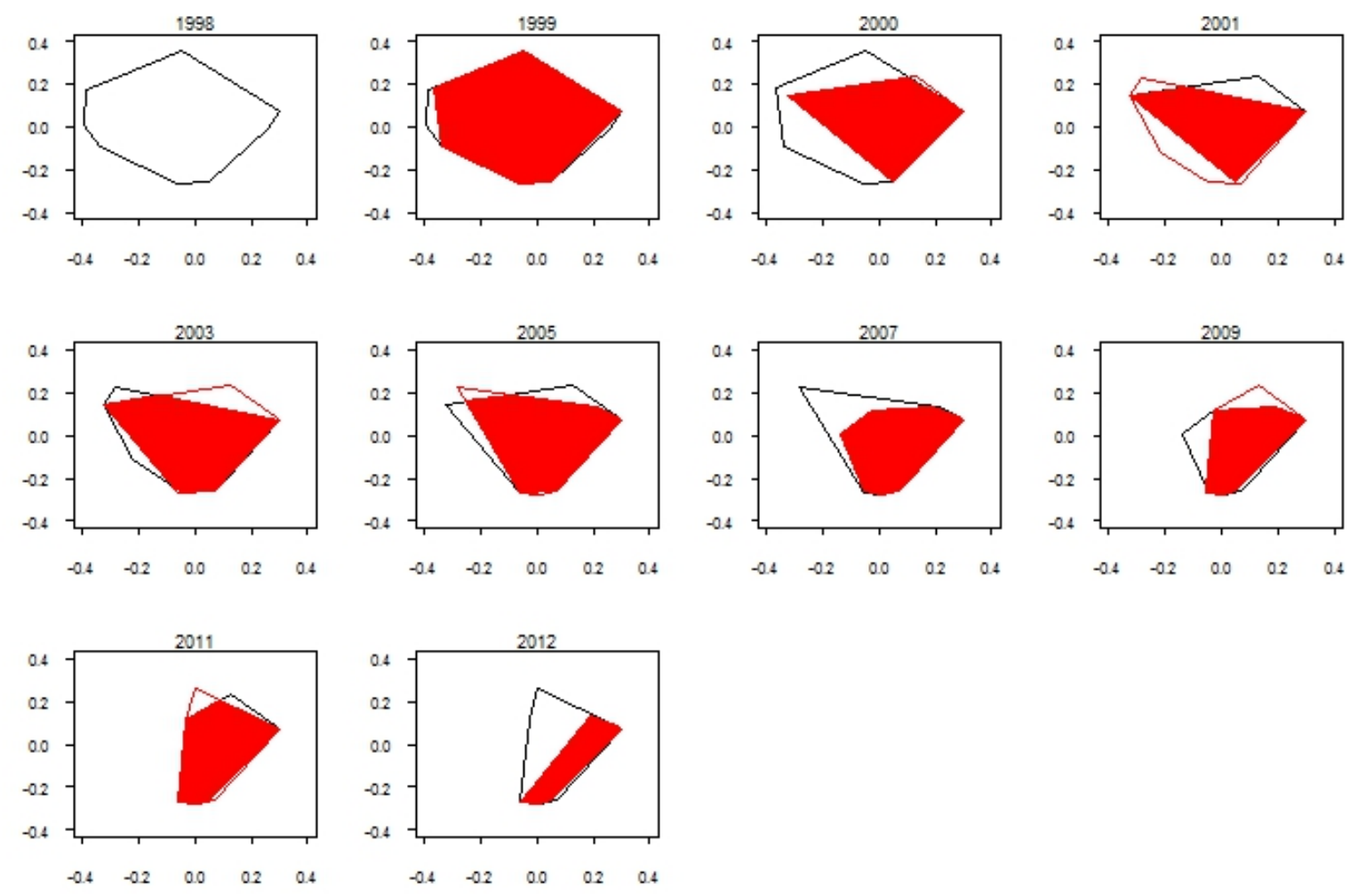
Figure 5

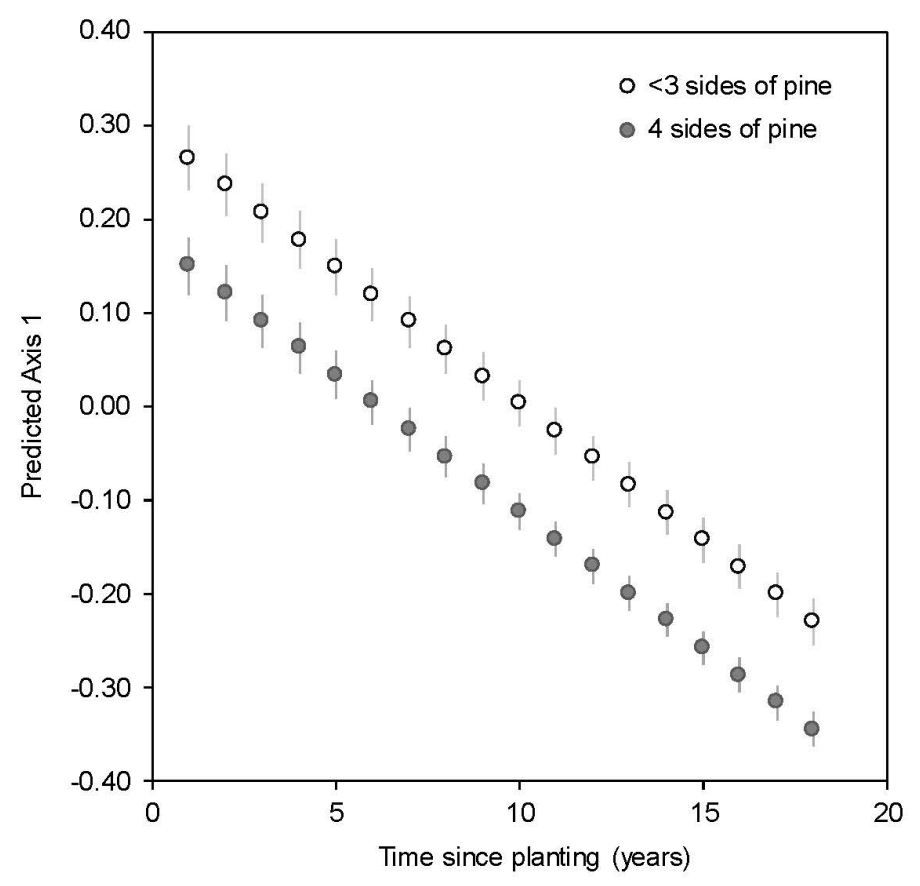


Figure 6

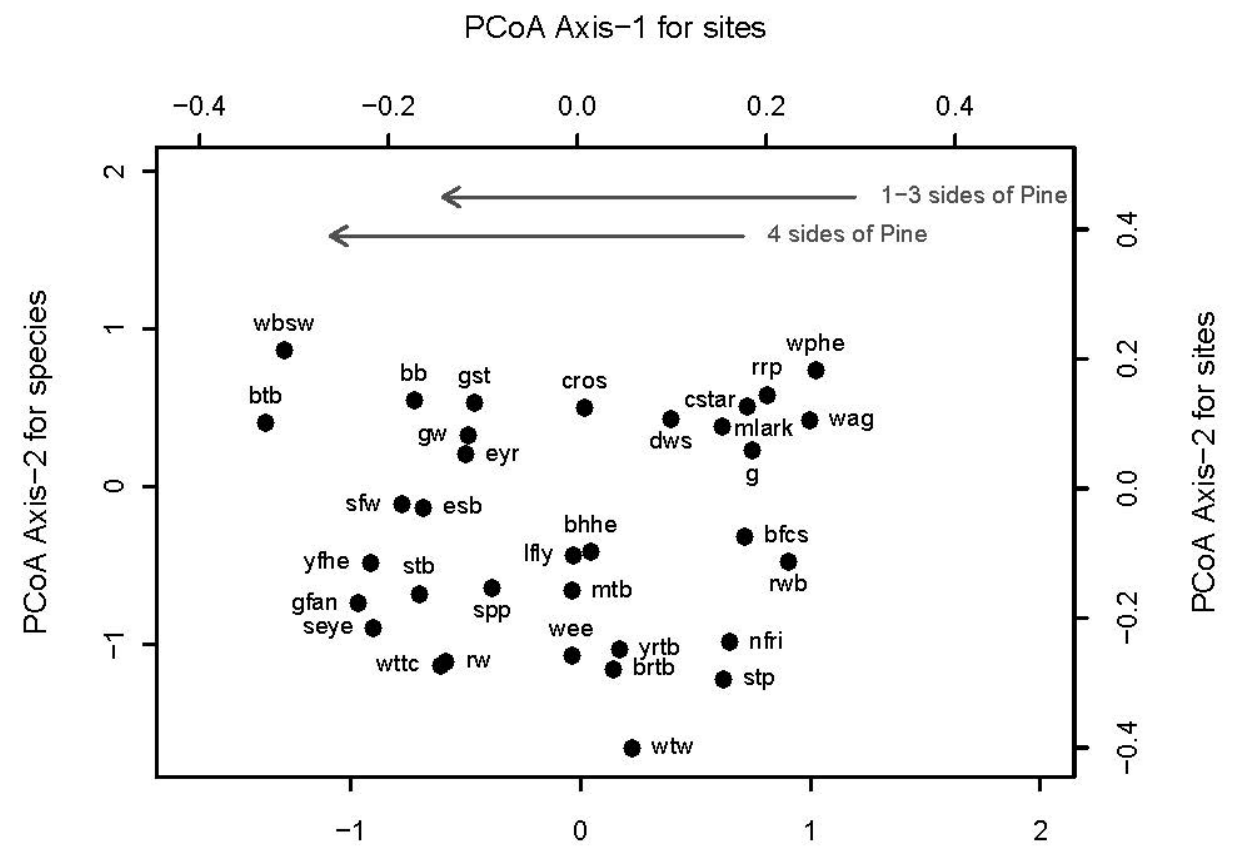

PCoA Axis-1 for species 